\title{
The Glint of a Mirror on a Boat on Rough Seas Observed from a Distant Lighthouse - Eric Chilton
}

THERE COMES A TIME in one's writerly career when one's interest in the typical subject matter fades, the slice-of-life vignettes become tiresome, the usual pursuits seem worn-over, the at first unwavering commitment to realism does indeed-with the slightest perceptible flicker like the glint of a mirror on a boat on rough seas observed from a distant lighthouse-waver, and one is inclined to venture forth, timidly at first, but then with ever bolder forays into the tempting realm of experimental fiction, testing the limits and then ignoring them, teasing the reader with ever-more abstract polemics, ever-increasing belligerence, until finally one finds oneself attempting that most elitist and nihilistic of forms: the metafictional short story. This is no such story. I refuse to submit myself (or my readership) to such an egotistical and ultimately fruitless exercise. What tripe! I am disgusted with their feeble answers to modernism, their self-conscious self-aggrandizing self-serving overly-and-exclusively-academic pap. Take, for example, one unnamed author's flubbed and brutal attempt:

The reader! You, dogged, uninsultable, print-oriented bastard, it's you I'm addressing, who else, from inside this monstrous fiction. Hey! Hi! It's me; I am diverting this passage (I'm the one writing the story you're now reading) and insisting that it be read with ironic distance.

I cannot stand for insolence of this variety. There will be no such attempts to drag the readership out of its passivity (well-deserved!) nor any reason to distinguish particular readers, and if I should happen to slip into the second person and say (I hesitate) "you," then rest assured that my intention is not to disrupt but only to address that hypothetical and non-threatening construct, The Reader. Are we to be convinced by a few attention-grabbing stuntmen confined to academic isolation? Has fiction as we know it become infected with an unshakable curse of avant-gardist gaming, of selfreferential loops? Are writers required to be droll manufacturers of some 
fickle literary fashion? Not this story. Not this author. I am a short-story writer in the grand American tradition. This is to be a conventional, realistic story with substantial characters and abundant human interest set in whatever locale I decide on (probably somewhere in America) in the later twentieth century.

There are two of interest, a woman and a man. The woman, Judith Valenzuela, lives at 42 Parsing Road, Carmel, CA 92502-8804. This information is provided to establish an appropriate level of detail and realism, because she is not actually at this address for most of the duration of the story; instead, she is on a mid-sized sport-fishing boat (to be described later) in Monterey Bay, not too far from shore. The man, Arnold Cooper, resides at 1420 Lakeside Drive, \#104, Hebrides, CA 92404. Their phone numbers have been withheld for legal reasons, and certainly not to "protect the innocent," for none of the characters in this story is innocent; to the contrary, each inhabits the real world where circumstances sometimes require certain indiscretions, like the time when Arnold was forced to expedite his extraction from a situation, a rather gruesome accident, the end result being that he paid the owner of the horse two hundred dollars and drove off. Remember that Arnold lives in Hebrides; this is not a nebulous idea or a conceit, it is a town. As evidence I offer this tidbit: the locals pronounce the name in two syllables and with long vowels (Hee-brides) and not like its namesake islands west of Scotland (Heb-rid-ease). However, like Judith, Arnold, in this story, is not in his home. He is at the top of a lighthouse that overlooks Monterey Bay.

Judith and Arnold are connected by more than their both being in this story. They are both part-time students at nearby Monterey Community College. They met seven months ago when they were both enrolled in Business Ethics 204. I could provide a syllabus and a sample of the typical classroom fare, but I don't need to-this is what is important: Arnold believes he loves Judith, but Judith does not love Arnold. They dated informally for four months, on weekends (usually dinner before a movie) and sometimes after class (Tuesday nights) at The Ground Hound, a coffee-shop across the street, but Judith's interests drifted elsewhere. To be honest she was never very serious about Arnold-he was intellectually immature and physically no more attractive than in the pedestrian, hormonal way-so she cut the relationship off as soon as she sensed him asking 
for more of her time. They had had sex three times under varying levels of intoxication. After the second time, lying in bed in Arnold's modest but clean apartment, Judith, stroking her "silky" (her descriptor) black hair, remarked, "Arnold, we should go other places. There are so many places to go around here." Arnold, his hands knotted behind his head, uttered, "Do you mean now?"

\section{The Guint}

It is important that I describe exactly the glint. This is no Symbol, no Metaphor, this is a glint! It exists in time and space; it has a certain intensity, duration, angles of reflection and refraction. Glints are usually noticed only as the end of their long journey, but for clarity I will track this one from the start. An immense gathering of molecules condenses in our sun, pushing in upon themselves via the force of gravity to such an extent that they inspire a nuclear reaction at the sun's core, this energy traveling outward to the surface through various electro-chemical reactions until it exists as light, hurling for eight and a half minutes towards the planet earth, passing through the atmosphere at a steep enough angle to avoid deflection, continuing, happening to arrive at the vicinity of Monterey Bay where it strikes the surface of a shiny object . . wait. There is no need to be coy. This shiny object is a mirror, and for a fuller description refer to the next section of this story. Go ahead. This is not a trick of the kind one might find in an "experimental text"; my intentions are pure and I do not want to make any dandiest claims, nothing about the tyranny of narrative progression or anything like that. Anyway: the light reflects off the mirror at an angle of 32.4 degrees, proceeding in the direction of the top of the lighthouse, where it is observed (the observation, too, will be described later). This leaves only one thing to be clarified. In my description of the evolution of the glint, I have not accounted for the innovations of quantum mechanics, the indeterminacy of light as wave or particle, the hedging of explicit claims in terms of probability factors, and so on. Brevity requires this omission. Be confident that my crude portrayal captures the essential elements of this story-event. Sunlight glints. 


\section{The Mirror}

It is Judith's mirror. She carries it in her purse for what she refers to as the Facial Contingencies, changes in light or occasion that require her to make slight (or sweeping) alterations to her eyeshadow, her lip-gloss, her hair, all with a dexterity mastered during her formative years. The mirror is in this story for the usual reason, specifically as an aid while Judith smoothes down her left eyebrow. She is on the boat, mirror in hand, smoothing her eyebrow; this is when the glint occurs. Astute readers may have at this point made a dangerous, speculative connection. Recognizing certain elements - a mirror, a tower (lighthouse), a paradigm of the artist (albeit in facial cosmetics, an underappreciated medium)-this hypothetical reader, too quick for his own good, may have leapt to the conclusion that this story mimics another in the literary canon: Tennyson's "The Lady of Shalott." It could not be coincidence, this reader thinks wrongly. Let me be clear. This story is not a retelling of "The Lady," a poem already bowed under the weight of its own self-consciousness. Judith Valenzuela is not a modern reincarnation of the Lady, released from bondage in the tower but ironically still confined to a life of artificial, superficial reflection. Arnold Cooper is not Tennyson's pompous Sir Lancelot, here appearing in the tower as a clever reversal. This story is not connected to Tennyson's poem. What matters is that Judith is peering into her mirror, seeing not the sun (that could cause permanent damage to her retina), but the upper left quadrant of her own face. It is Arnold, from atop the lighthouse, who glimpses through the mirror the sun, its light angled around Judith's head.

\section{THE BOAT}

23 foot, dual outboard engines, $140 \mathrm{Hp}$ manufacturer: Boston Whaler Marine Co.

name: Kingfisher II

dock: Pacific Grove Marina

color: Massachusetts White with Caribbean Blue detailing

primary use: day fishing for small private parties

owner: John Lisburn

The human interest in this story is abundant. Arnold is in the lighthouse, Judith is on the deck of the boat, but that is not all; there is another man. 
Namely, John Lisburn, the owner of the boat. John harbors amorous intentions for Judith, and Judith, so far, seems willing to reciprocate. She has accepted his invitation to spend the afternoon on his boat, even though she's not particularly fond of the water and certainly not of fish. That's where John is now, fishing from the prow, near which he saw a school, and that's why Judith has taken this moment to observe her eyebrow via her pocket mirror (see previous section).

\section{The Rough Seas}

Before moving on I should make something clear. The seas in this story are not, perhaps, as rough as one might assume when one sees the phrase "rough seas." The adjective was used to indicate motion-the boat is not on flat water-and to describe the relative roughness of these particular seas, for Monterey Bay is usually calm and well-mannered; today there are two-tothree foot swells. I have clarified all this in the hopes of nipping in the bud any notions about authorially imposed drama, false outward signs of the inner turmoil and the like. Nothing could be further from my intent. This story has no more and no less "drama" than real life as we all experience it. The nature of the water is rougher than usual; this is provided for informational purposes. The boat is rocking slightly, and while it crests lazily over a swell the sunlight is directed, via Judith's mirror, towards the lighthouse.

I just removed a lengthy and rather self-indulgent paragraph which had speculated on some personal issues in this story. It was overly self-conscious and tedious. However, I, unlike certain too-celebrated "experimental" authors, have done my audience the favor of editing out such sections carefully. I have no wish to make the reader endure haughty intellectual showboating.

\section{The Observing}

Performed by Arnold Cooper, whom we have already met. For clarity's sake, though, a rehash: Arnold Cooper had been watching Judith on the boat through his binoculars (he tracked their cruise all the way from the marina). but now he has lowered his binoculars; this is when he sees the glint. Some more details, since this story, like real life, does not take place 
without context (there are histories of characters and complexities of relationships): Arnold still loves Judith and so is compelled to pursue her, despite his awareness of John Lisburn. It is true that after they broke up Arnold phoned Judith seven times without getting a response, and it is true that over the past few weeks he has devoted some (not all) of his time to following her, but this is only because he has a strong conviction that she needs him, that she is quietly calling out to him. The following is what led him to the lighthouse; he learned she was going on a short cruise so he came to the lighthouse. So: Arnold-observing, from the lighthouse, a glint of sunlight in his lover's mirror, coming from a boat (the boat belonging to his amorous competitor) on relatively rough seas-Arnold drops his binoculars and ...

\section{The Distant Lighthouse}

This interruption is not gratuitous. To the contrary, it is required in order to provide some physical details of the lighthouse, which will be crucial if we are to fully understand Arnold's reaction to the glint. The lighthouse is not a panopticon, not a motif for the totalitarian state, not a phallic symbol, it is a lighthouse, 127 feet tall and painted mostly white. At the top, above the actual light, there is a small viewing deck (where Arnold is) with high rails and a wrought-iron bench. Recall that we left Arnold as he dropped his binoculars; they fall to the deck and one lens cracks. He has seen the glint. $\mathrm{He}$ interprets the glint as a signal for help. He thinks that John Lisburn has revealed his monstrous nature; alone with Judith on the boat he is going to beat her and rape her. She must have flashed her mirror as a last call for Arnold's help. Straight away Arnold begins fantasizing scenarios in which he rescues Judith. He imagines swimming out to her, climbing into the boat and punching John Lisburn, et cetera and so on. Arnold sits on the bench to concentrate, working mentally through all the possibilities. Judith, right now, is still on the boat; the eyebrow is smoothed.

There is no need for a coda or authorial commentary of that sort. The story will stand on its own. This story is like real life. There is no artificial sense of closure, and what closure there is is passing. 